\title{
Smoking Cessation Behaviors and Reasons for use of Electronic Cigarettes (EC) and Heated Tobacco Products (HTP) Among Romanian Adults: Implications for Comprehensive Tobacco Control Policy
}

\section{Sumaira Hussain}

International Medical University

Chandrashekhar T Sreeramareddy ( $\nabla$ chandrashekharats@yahoo.com ) International Medical University

Research Article

Keywords: electronic cigarettes (EC), heated tobacco products (HTP)

Posted Date: December 14th, 2021

DOI: https://doi.org/10.21203/rs.3.rs-1115565/v1

License: (c) (1) This work is licensed under a Creative Commons Attribution 4.0 International License. Read Full License 


\section{Abstract}

We report cessation behaviors, reasons for use of EC and HTP and association of their use with quit attempts and smoking intensity using Romania Global Adult Tobacco Survey 2018. Weighted estimates of EC and HTP by cigarette smoking (CS) status were assessed. 'Quit attempts', 'intention to quit', reasons for lack of intention to quit among current CS and reasons for current use of EC and HTP were estimated. Association of 'ever use' of EC and HTP with cigarette smoking intensity and quit attempts was explored using binary logistic regression. Of the total 4571 surveyed, $1243(27.3 \%)$ were current CS, $300(24.4 \%)$ made quit attempt in the past 12 months. Only $38(12.5 \%)$ and $26(8.6 \%)$ had used EC and HTP as an aid to quit. Among current CS, $512(41.2 \%)$ had no intention to quit. Reasons for this were, 'enjoy smoking' (86.1\%), 'reduce stress' (65.9\%) and 'staying alert' (46.3\%). Awareness and use of EC and HTP was significantly higher among current CS. 'Dual use' of EC and HTP with CS was manifolds higher than stand-alone use. Reasons for current use of EC and HTP were 'enjoyment', and 'use in places where smoking was prohibited'.

\section{Introduction}

As early as 1940, the causal association between cigarette smoking (CS) and lung cancer was made. ${ }^{1}$ CS attributes to about of eight million deaths globally each year. ${ }^{2}$ Globally prevalence of CS has gradually declined. ${ }^{3}$ Just when a target for 'tobacco endgame' was set by World Health Organization $(\mathrm{WHO})^{4}$, novel tobacco products such as electronic cigarettes (EC) followed by heated tobacco products (HTP) emerged and they are being marketed as harm-reduction substitutes ${ }^{5 ; 6}$. This coupled with their easy accessibility has brought about a significant change in dynamics of tobacco use epidemiology since the regulatory policies for EC and HTP vary widely across the countries ${ }^{7}$.

Evidence is unclear if ECs are useful in assisting cessation of $\mathrm{CS}^{8}$ even though they are often initiated with the intent of quitting $\mathrm{CS}^{9}$. However, emerging evidence reports that EC use among current $\mathrm{CS}$ increases future smoking initiation among youth, increases the odds of transition to poly-tobacco use (PTU) ${ }^{10 ; 11}$ among current CS and acts as a gateway to CS among non-smokers. ${ }^{12 ; 13}$ Recently, HTP use has also been reported to be increasing in some countries. ${ }^{14-17}$ HTP are also promoted as a harm reduction product to aid in smoking cessation. ${ }^{6}$ Although EC and HTP are marketed as less harmful substitutes to conventional cigarettes, they are still potentially harmful to human health, propelling the debate on their utility. $5 ; 8 ; 18 ; 19$

Romania, a signatory to WHO Framework Convention on Tobacco Control (FCTC), ${ }^{20}$ has launched a national campaign, "the First Generation without Tobacco" 21 , that endorses the WHO 'tobacco end game' by $2035^{4}$. Regardless, the prevalence of current CS remained high at $34.0 \%$ (females: $29.5 \%$ and males: $38.7 \%$ ) in $2017 .{ }^{22}$ As use of EC and HTP is rising in European countries, ${ }^{22-24}$ Romania follows the trend with 'ever use' of EC at $8.8 \%$ in $2014{ }^{23}$ and 'ever use' of HTP at $4 \%$ in $2018 .{ }^{14}$ Increasing use of these newer and apparently safer tobacco products makes it imperative to understand cigarette smoking 
cessation behaviors ${ }^{25 ; 26}$ and reasons for use of EC and HTP. ${ }^{9 ; 27}$. The most recent GATS in Romania (2018) includes detailed questions about use of EC and HTP. We aim to study smoking cessation behaviors, distribution of EC and HTP use behaviors according to CS status, and reasons for current use of EC and HTP. We also explored the association of 'ever use' of EC and HTP with cigarette smoking intensity and quit attempts.

\section{Methods}

Romania Global Adult Tobacco Survey 2018 obtained ethical approvals from Centre for Disease Control, Atlanta, United States and National Institute of Public Health. Informed consent for participation was obtained from each selected participant. A separate ethical approval was not required since de-identified publicly available data was used to prepare this report. The study was carried out in compliance with Declaration of Helsinki and followed all relevant guidelines and regulations.'

\section{Data Source}

A secondary data analyses of Romania, Global Adult Tobacco Survey, 2018 was done. GATS is a nationally representative household survey of adults 15 years old and above that monitors adult tobacco use and tracks key tobacco use indicators. GATS uses a standardized methodology. It includes information on respondents' background characteristics, tobacco use (cigarette smoking, smokeless tobacco, e-cigarettes, and heated tobacco products), cessation behaviors, exposure to secondhand smoke, economics, media, and knowledge, attitudes, and perceptions towards tobacco use. In Romania, GATS was conducted in 2018 by National Institute of Public Health, and Totem Communication under the coordination of Romanian Ministry of Health and WHO Country and Europe Regional Office. A multistage, geographically clustered sample design was used to produce nationally representative data. A total of 5,408 households were sampled. One individual was randomly chosen from each selected household to participate in the survey. Survey information was collected using handheld devices. Detailed methods of GATS are published elsewhere. ${ }^{28}$

\section{Outcome variables}

The outcome variables were defined based on the response options to questionnaire items in Romania GATS 2018 and are summarised in Appendix A. The main outcome variables were 'awareness' about EC and HTP, 'ever use' of EC and HTP, 'current' CS, 'current' use of EC and HTP, 'former' CS and 'former' use of EC and HTP. Briefly, 'awareness' was defined if response was 'yes' to items 6 and 10. Questions regarding use of EC and HTP were asked to only those adults who were 'aware' of EC and HTP. 'Ever use' was defined if response was 'yes' to questions 7 and 11. 'Current use' if response was either 'daily' or 'less than daily' to questions 1, 8 and 12. 'Former' CS or 'former' EC use and HTP use was defined if response was 'yes' to questions 2, 9 and 13 respectively (Appendix A). Current CS were asked, "Which of the following 
best describes your thinking about quitting smoking?". "Which of the following are major reasons for why you are not interested in quitting smoking?" was asked to the individuals who responded as "not interested in quitting" (figure 1). Current EC and HTP users were asked "Which of the following are reasons that you use electronic cigarettes/ heated tobacco products?". The responses were recorded as 'yes', 'no' or 'refused' for identical options given to both EC and HTP.

\section{Predictor Variables}

The predictor variable definitions were based on the response options to GATS questionnaire; they can be divided into sociodemographic factors and tobacco associated factors. Operationalization predictor variables is shown in appendix B. Sociodemographic factors are: type of residence (urban/rural); sex; age group (15-24, 25-40, 41-55, 56-70 and $\geq 71)$; educational attainment [no education/primary, secondary, high school and higher education (college, university)]; wealth category [divided into quintiles from 1 (poorest) to 5 (richest)] based on the principal component analyses of a list of household assets; and primary occupation in the last 12 months [government employee, non-government or self-employed, student/homemaker and others (retired, unemployed, unable to work)]. Operationalization of tobaccorelated variables are summarized in Appendix B. They include: number of sticks smoked per day $(\leq 10$, $10-20$ and $\geq 20$ ); rules about smoking at home as 'permitted' (allowed), 'prohibited' (allowed with exceptions and not allowed) and 'no rules'; knowledge score about health complications of smoking (maximum possible score was 12); sources of exposure to information about dangers of CS, EC and HTP, (exposed to 'at least one' or 'none'); and sources of exposure to promotional materials about CS and HTP ('at least one' or 'none').

\section{Statistical analyses}

Descriptive statistics of raw and weighted numbers and proportions, means and weighted prevalence estimates and their $95 \%$ confidence intervals $(95 \% \mathrm{Cl})$ were calculated. Survey weights were used to account for the complex sampling design of GATS. Socio-demographic and tobacco-related factors associated with current CS and 'ever use' of EC and HTP were determined by binary logistic regression using 'svy command. Adjusted odds ratios (aOR) and their $95 \% \mathrm{Cl}$ were estimated. A p-value $<0.05$ was considered as statistically significant. All analyses were done on Stata/MP version 11 .

\section{Results}

The household response rate was $90.6 \%$, the person-level response rate was $97.1 \%$, and overall response rate was $88.0 \%$. There was a total of 4,571 completed individual interviews. The socio-demographic characteristics of the respondents are shown in Table 1 as raw and weighted numbers and percentages. Among the adults surveyed, the proportion from urban residence was higher (56.9\%) than rural and female respondents were slightly more $(51.6 \%)$ than males. About $55 \%$ of the adults surveyed were aged $25-55$ years. Most adults were educated up to high school (44.2\%) or higher (22.7\%). Higher proportions 
of adults belonged to the wealth category of poorest $(25.6 \%)$ and poorer $(20.6 \%)$ and majority held the occupational category of non-governmental or self-employed (39.3\%). 
Table 1

Raw and weighted numbers and proportions of socio-demographic characteristics of adults in Romania GATS 2018

\begin{tabular}{|c|c|c|}
\hline & Raw number (\%) & Weighted number (\%) \\
\hline \multicolumn{3}{|l|}{ Type of residence } \\
\hline urban & $2318(50.7)$ & $10496537(56.9)$ \\
\hline rural & $2253(49.3)$ & 7955787 (43.1) \\
\hline \multicolumn{3}{|l|}{ Sex } \\
\hline Male & $2111(46.2)$ & $8939290(48.5)$ \\
\hline Female & $2460(53.8)$ & $9513034(51.6)$ \\
\hline \multicolumn{3}{|l|}{ Age groups } \\
\hline $15-24$ & $343(7.5)$ & $2171286(11.8)$ \\
\hline $25-40$ & $997(21.8)$ & $5439022(29.5)$ \\
\hline $41-55$ & $1066(23.3)$ & 4707914 (25.5) \\
\hline $56-70$ & $1376(30.1)$ & $4220688(22.9)$ \\
\hline$\geq 71$ & 789 (17.3) & $1913414(10.4)$ \\
\hline \multicolumn{3}{|l|}{ Educational Attainment } \\
\hline No/primary & $428(9.5)$ & $1,197,463(6.6)$ \\
\hline Secondary & $1346(29.9)$ & $4,807,753(26.5)$ \\
\hline High school & $1812(40.3)$ & $8,032,612(44.2)$ \\
\hline Higher education & $916(20.4)$ & $4,126,121(22.7)$ \\
\hline \multicolumn{3}{|l|}{ Wealth category } \\
\hline Poorest & $985(21.6)$ & $4718235(25.6)$ \\
\hline poorer & $731(16.0)$ & 3799781 (20.6) \\
\hline Middle & $600(13.1)$ & 2742219 (14.9) \\
\hline richer & $1160(25.4)$ & $3877398(21.0)$ \\
\hline Richest & $1095(24.0)$ & $3314692(18.0)$ \\
\hline \multicolumn{3}{|l|}{ Occupation } \\
\hline Government employee & $423(9.3)$ & $2,090,359(11.4)$ \\
\hline Non-governmental or self-employed & $1461(32.2)$ & $7,200,990(39.3)$ \\
\hline
\end{tabular}




\begin{tabular}{|lll|}
\hline & Raw number (\%) & Weighted number (\%) \\
\hline Student/homemaker & $741(16.3)$ & $3,593,117(19.6)$ \\
\hline Others (retired, unemployed, unable to work) & $1916(42.2)$ & $5,438,952(29.7)$ \\
\hline
\end{tabular}

\section{Tobacco Use Behaviours}

Weighted prevalence (\%) estimates of tobacco use behaviors are shown in Table 2. Weighted estimates of 'awareness' and 'ever use' were $76.4 \%(95 \% \mathrm{Cl}: 74.3,78.6)$ and $7.8 \%(95 \% \mathrm{Cl}: 6.8,8.9)$ for EC; $30.1 \%$ (95\% Cl: $27.6,32.6)$ and 3.0\% (95\% Cl 2.2, 3.8) for HTP. Weighted prevalence 'current use' and 'former use' was $30.2 \%$ (95\% Cl: $28.1,32.3)$ and $12.5 \%$ (95\% Cl: $11.2,13.8)$ for CS, $3.4 \%(95 \% \mathrm{Cl}: 2.6,4.1)$ and $3.2 \%$ (95\% Cl: $2.5,3.8)$ for EC, $1.3 \%$ (95\% Cl: $0.9,1.7)$ and $0.6 \%(95 \% \mathrm{Cl}: 0.3,0.9)$ for HTP. Mean age at initiation of daily CS was 21.1 years ( $95 \% \mathrm{Cl}$ : 16.8, 25.4). Mean age at trial (even once) of EC was 32.6 years ( $95 \%$ Cl: $26.4,38.8)$ and HTP was 36.3 years ( $95 \% \mathrm{Cl}: 29.5,43.2)$. Mean knowledge scores about the health complications of CS were 8.09 (95\% Cl: 7.77, 8.42), 8.47 (95\% Cl: 8.12, 8.82), 8.91 (95\% Cl: 8.69, 9.14) among the current CS, HTP and EC users respectively.

Table 2

Tobacco product use behaviors, and knowledge about health effects of CS among adults in Romania GATS 2018

\begin{tabular}{|c|c|c|c|}
\hline Prevalence & $\mathrm{EC}(95 \% \mathrm{Cl})$ & HTP $(95 \% \mathrm{Cl})$ & CS $(95 \% \mathrm{Cl})$ \\
\hline Awareness (Wt. prev. \& 95\% Cl) & $76.4(74.3,78.6)$ & $30.1(27.6,32.6)$ & - \\
\hline Current use (Wt. prev. \& 95\% Cl) & $3.4(2.6,4.1)$ & $1.3(0.9,1.7)$ & $30.2(28.1,32.3)$ \\
\hline Former use (Wt. prev. \& 95\% Cl) & $3.2(2.5,3.8)$ & $0.6(0.3,0.9)$ & $12.5(11.2,13.8)$ \\
\hline Ever use (Wt. prev. \& 95\% Cl) ${ }^{£}$ & $7.8(6.8,8.9)$ & $3.0(2.2,3.8)$ & $42.7(44.8,40.5)$ \\
\hline Age at initiation (Mean, 95\% Cl) & $32.6(26.4,38.8) ¥$ & $36.3(29.5,43.2) ¥$ & $21.1(16.8,25.4)^{\times}$ \\
\hline Knowledge score (Mean, 95\% Cl) & $8.91(8.69,9.14)$ & $8.47(8.12,8.82)$ & $8.09(7.77,8.42)$ \\
\hline \multicolumn{4}{|c|}{${ }^{£}$ ever CS was those who has ever smoked during lifetime i.e., current, and former CS, } \\
\hline \multicolumn{4}{|l|}{${ }^{\times}$age at which initiated daily smoking } \\
\hline \multicolumn{4}{|c|}{$¥$ age at which tried EC or HTP even once } \\
\hline${ }^{€}$ estimated for only current CS a & are of $\mathrm{EC}$ and $\mathrm{H}$ & & \\
\hline
\end{tabular}

\section{Comparison Of Ec And Htp By Cigarette Smoking Status}


The distribution of EC and HTP awareness and use by CS status are shown in Table 3. Both current and ever use of EC and HTP were much higher among individuals engaged in current CS than those adults who were former CS and never CS. For example, proportion who were current EC users was 8.13, 1.25 and 0.37 among current CS, former CS and never CS respectively. A similar pattern was observed for current HTP use (Table 3). EC and HTP use were several-folds higher among current CS than former and never CS. Most notable was current 'dual use' i.e., CS and EC, CS and HTP were $8.1 \%$ and $3.6 \%$ respectively. Polytobacco use (CS+EC+HTP) was $2.9 \%$.

Table 3

Proportions (\%) of EC and HTP awareness and use by adults according to their CS status (current, former, and never)

\begin{tabular}{|llllll|}
\hline & Entire sample & Current CS $(\mathbf{n = 1 2 4 3 )}$ & $\begin{array}{l}\text { Former CS } \\
(\mathbf{n = 6 3 8})\end{array}$ & $\begin{array}{l}\text { Never CS } \\
(\mathbf{n = 2 6 9 0})\end{array}$ & p-value \\
\hline EC & & & & & \\
\hline Awareness & 70.8 & 87.4 & 80.1 & 61.0 & $<0.001$ \\
\hline Ever use & 6.8 & 18.8 & 6.9 & 1.2 & $<0.001$ \\
\hline Current users & 2.6 & 8.1 & 1.3 & 0.4 & $<0.001$ \\
\hline HTP & & & & & \\
\hline awareness & 23.7 & 37.9 & 24.0 & 17.1 & \\
\hline Ever use & 2.3 & 6.0 & 2.2 & 0.7 & $<0.001$ \\
\hline Current use & 1.1 & 3.6 & 0.6 & 0.04 & $<0.001$ \\
\hline
\end{tabular}

\section{Smoking cessation behaviors, and reasons for "no intention to quit" CS}

Figure 1 shows the distribution of survey sample by cigarette smoking status, smoking cessation behaviors and reasons for 'no intention to quit'. Of the total 4571 surveyed, 1243 (27.3\%) were involved in current CS. Only 300 (24.4\%) of current CS had 'tried to quit smoking' during past 12 months. Of these 300 , only $38(12.5 \%)$ and $26(8.6 \%)$ had tried using EC and HTP respectively to quit CS (Figure 1A). Among current CS, 512 (41.2\%) were 'not interested at all' in quitting smoking (Figure 1B). The common reasons cited for this were 'like to smoke' (86.4\%), 'smoking helps to reduce stress' (65.9\%), 'smoking helps to keep alert' (45.1\%), 'do not have the confidence that they can quit' (44.7\%) and 'do not believe smoking is injurious to health' (39.8\%) (Figure 1C). Weighted numbers and percentages are shown in etable 1.

\section{Raw numbers and proportions, and reasons for current use of EC and HTP use}

Figure 2 provides raw numbers about awareness of EC and HTP, their usage, and reasons for use among 'current' users. Of the 4571 adults surveyed, 3271 (70.8\%) and 1085 (23.7\%) were aware about EC and 
HTP respectively (Figure 2A). Of those aware 113 (3.7\%) and $47(2.0 \%)$ were current users of EC and HTP respectively (Figure 2B). Reasons cited for current EC use were ECs are 'less harmful than tobacco smoking' (49.7\%), EC can be 'used when or in places when smoking cigarettes was prohibited' (62.4\%), 'to avoid smoking' (58.7\%), 'enjoy using EC' (52.1\%) and 'to quit smoking' (58.9\%). Reasons for current HTP use were: 'enjoy using HTP' (67.9\%), 'less harmful than smoking' (58.7\%), and HTP can be 'used when or in places when smoking was prohibited' (79.0\%) (Figure 2B). Weighted numbers and percentages are shown in e-table 2.

\section{Factors associated with current CS and 'ever use' of EC and HTP}

Tables 4 shows the results of binary logistic regression for factors associated with current CS and 'ever use' of EC and HTP. After adjusting for individual and tobacco related factors, current CS was associated with male sex, rules about smoking at home, exposure to information about dangers of smoking, cigarette promotional materials and knowledge score about health complications of smoking (Table 4). Men had twice higher odds (aOR: $2.1,95 \% \mathrm{Cl}: 1.7,2.7$ ) of engaging in current CS than women. Adults from homes where smoking was prohibited had 0.2 times lower odds ( $95 \% \mathrm{Cl}: 0.1,0.2)$ of CS than those from homes where smoking was permitted. Adults exposed to at least one source of information about dangers of smoking and higher knowledge score of health complications of smoking had $0.8(95 \% \mathrm{Cl}$ : $0.6,1.0)$ and $0.9(95 \% \mathrm{Cl}: 0.9,1.0)$ lower odds of engaging in CS whereas those individuals exposed to at least one cigarette promotional material had 1.7 higher odds $(95 \% \mathrm{Cl}: 1.3,2.1)$ of participating in CS compared to adults who were not exposed to any. 
Table 4

Factors associated with manufactured current CS, ever use EC and HTP.

Current Cigarette E-cigarette Ever Use $\quad$ Ever Use of HTP
Smoking

\begin{tabular}{lllllll} 
& $\begin{array}{l}\text { Adj. OR } \\
(95 \% \mathrm{Cl})\end{array}$ & $\begin{array}{l}\text { p- } \\
\text { value }\end{array}$ & $\begin{array}{l}\text { Adj. OR } \\
(95 \% \mathrm{Cl})\end{array}$ & $\begin{array}{l}\text { p- } \\
\text { value }\end{array}$ & $\begin{array}{l}\text { Adj. OR } \\
(95 \% \mathrm{Cl})\end{array}$ & $\begin{array}{l}\text { p- } \\
\text { value }\end{array}$ \\
\hline Residence & & & & & & \\
\hline Rural & 1 & & 1 & & 1 & \\
\hline Urban & $1.1(0.8,1.4)$ & 0.516 & $1.7(1.1,2.7)$ & 0.027 & $2.3(1.0,5.4)$ & 0.063 \\
\hline Sex & & & & & & 1 \\
\hline Female & 1 & & 1 & & & \\
\hline Male & $2.1(1.7,2.7)$ & $<0.001$ & $1.3(0.8,2.1)$ & 0.308 & $1.2(0.5,3.1)$ & 0.623 \\
\hline Age groups & & & & & & \\
\hline $15-24$ & 1 & & 1 & & 1 & \\
\hline $25-40$ & $1.0(0.7,1.5)$ & 0.949 & $0.8(0.4,1.5)$ & 0.424 & $0.5(0.2,1.3)$ & 0.137 \\
\hline $41-55$ & $1.1(0.8,1.7)$ & 0.56 & $0.6(0.3,1.3)$ & 0.179 & $1.0(0.3,3.1)$ & 0.985 \\
\hline $56-70$ & $0.7(0.5,1.2)$ & 0.221 & $0.4(0.2,1.1)$ & 0.074 & $0.3(0.0,2.0)$ & 0.218 \\
\hline$\geq 71$ & $0.1(0.1,0.3)$ & $<0.001$ & $0.6(0.1,4.3)$ & 0.638 & & \\
\hline
\end{tabular}

\section{Educational attainment}

\begin{tabular}{|c|c|c|c|c|c|c|}
\hline No/primary & 1 & & 1 & & 1 & \\
\hline Secondary & $1.6(0.9,3.0)$ & 0.123 & $7.1(0.8,67.7)$ & 0.087 & - & \\
\hline High school & $1.1(0.6,2.0)$ & 0.853 & $\begin{array}{l}11.1 \text { (1.1, } \\
109.6)\end{array}$ & 0.039 & $\begin{array}{l}3.7(1.1 \\
11.6)\end{array}$ & 0.028 \\
\hline Higher education & $1.1(0.5,2.2)$ & 0.817 & $\begin{array}{l}13.5(1.3 \\
142.7)\end{array}$ & 0.03 & $\begin{array}{l}3.2(0.9 \\
11.7)\end{array}$ & 0.077 \\
\hline
\end{tabular}

\section{Wealth category}

\begin{tabular}{|lllllll|}
\hline Poorest & 1 & & 1 & & 1 \\
\hline Poorer & $1.1(0.8,1.5)$ & 0.425 & $1.9(1.0,3.5)$ & 0.038 & $0.7(0.3,1.5)$ & 0.334 \\
\hline Middle & $1.5(1.0,2.0)$ & 0.025 & $2.1(1.1,4.0)$ & 0.029 & $0.5(0.1,2.1)$ & 0.344 \\
\hline Richer & $1.3(0.9,1.8)$ & 0.176 & $1.4(0.7,2.6)$ & 0.34 & $0.0(0.0,0.3)$ & 0.001 \\
\hline Richest & $1.4(0.9,2.1)$ & 0.097 & $2.7(1.2,6.1)$ & 0.013 & $0.3(0.0,2.1)$ & 0.207 \\
\hline x retired, unemployed, unable to work etc. & & & & \\
\hline
\end{tabular}




\section{Current Cigarette E-cigarette Ever Use Ever Use of HTP Smoking}

\section{Occupation}

Government employee

Non-govt/selfemployed

$1.2(0.9,1.7)$

0.245

$1.2(0.6,2.5)$

0.585

$1.4(0.5,4.7)$

0.531

Student/homemaker

$0.6(0.4,0.9)$

0.017

$1.4(0.6,3.6)$

0.452

4.0 (1.0,

0.042 15.2)

Others $x$

$0.6(0.4,1.0) \quad 0.056$

$0.5(0.2,1.3)$

0.168

$4.4(0.9$,

0.07 22.1)

Rules about smoking at home

Permitted 1 1

1

Prohibited

$0.2(0.1,0.2)<0.001$

$0.8(0.5,1.2)$

0.232

$0.7(0.3,1.4)$

0.293

No rules

$0.3(0.2,0.4) \quad<0.001$

$0.7(0.3,1.6)$

0.391

$1.5(0.3,8.5)$

0.613

Knowledge score about health complications of smoking

$$
\begin{array}{llllll}
0.9(0.9,1.0) & <0.001 & 1.0(0.9,1.3) & 0.26 & 0.9(0.8,1.0) & 0.15
\end{array}
$$

\section{Exposure to information about dangers of CS}

$\begin{array}{llll}\text { None } & 1 & 1 & 1\end{array}$

$\begin{array}{lllllll}\text { At least one source } \quad 0.8(0.6,1.0) & 0.02 & 0.9(0.6,1.5) & 0.815 & 0.8(0.3,2.0) & 0.675\end{array}$

\section{Exposure to information about promotional materials about cigarettes}

None

At least one source
1

$1.2(0.8,1.9)$

0.36 1

Quit smoking attempts made during last 12 months

No

Yes

Number

$<10$

$11-20$

$>20$
1

$1.7(1.3,2.1)$

$<0.001$

(

$(2.36$

1

1

$1.5(0.7,3.3) \quad 0.277$

$\times$ retired, unemployed, unable to work etc. 


\section{Current Cigarette Smoking \\ E-cigarette Ever Use \\ Ever Use of HTP}

Exposure to information about dangers of EC

At least one source

1

None

$1.0(0.6,1.7) \quad 0.904$

\section{Exposure to information about dangers of HTP}

At least one source

1

None

$1.3(0.4,4.2)$

0.638

Exposure to information about promotional materials about HTP

At least one source

1

None

$0.9(0.4,2.1)$

0.82

$\times$ retired, unemployed, unable to work etc.

After adjusting for individual and tobacco related factors, 'ever use' (even once) of EC or HTP was associated with area of residence, wealth, educational attainment, attempt to quit smoking, and number of cigarettes smoked per day (Table 4). Individuals from urban areas had 1.7 (95\% Cl: 1.1, 2.7) higher odds of ever use of EC than those from rural areas. Similarly, the richest individuals had 2.7 (95\% Cl: 1.2, 6.1) higher odds for ever use EC and richer individuals had 0.01 times lower odds for ever use of HTP (aOR $0.01,95 \% \mathrm{Cl}: 0.01,0.3$ ) compared to the poorest. Individuals who had attained higher education had 13 times higher odds for ever use of EC (aOR $13.5,95 \% \mathrm{Cl}: 1.3,142.7)$ whereas adults educated up to high school education had 3.7 times higher odds for ever use of HTP (aOR 3.7, 95\% Cl: 1.1, 11.6). Adults who had tried to quit cigarette smoking in the past twelve months had $1.8(95 \% \mathrm{Cl}: 1.0,3.0)$ higher odds of ever use of EC. Individuals who smoked more than 20 cigarettes a day had 2.5 ( $95 \% \mathrm{Cl}$ : 1.2, 5.1) higher odds of ever use of EC.

\section{Discussion}

A secondary data analyses of GATS 2018 survey revealed that nearly a third of Romanian adults currently smoke cigarettes, which has not declined from GATS 2011. Only a quarter of current CS had made a quit attempt during past 12 months. More than a third had 'no intention to quit', mainly because they 'like to smoke', 'smoking reduces stress' and 'smoking helps keep alert'. Use of EC and HTP was several folds higher among individuals practicing current CS than never CS or former CS. Current 'dual use' of either EC and CS or HTP and CS was common, rather than use of EC or HTP alone. Use of either EC or HTP was seldom used as a smoking cessation aid by those who tried to quit. Perception that EC and HTP are 'less harmful than CS' and 'can be used in places where CS was prohibited' were common reasons for current use of EC and HTP. Ever use of EC was associated with attempt to quit CS and smoking $>20$ cigarettes per day. 
GATS 2018 shows that CS has increased relative to previous GATS 2011 and comparable survey reports. ${ }^{22 ; 29}$ However, notably, mean sticks smoked per day $(16.3,95 \% \mathrm{Cl} 15.5,17.0)$ remained unchanged from GATS 2011. GATS 2018 provides more robust estimates of EC and HTP than European surveys 14;23. Though awareness and ever use of EC has increased, current use of EC is still low. With HTP being a more recent product, estimates of awareness, ever and current use were lower and are comparable to previous surveys. ${ }^{14}$ Regardless of the marketing of EC and HTP as harm reduction agents and aides to quit CS, quit ratio (former CS/ ever CS) was only 0.3 in GATS 2018 and the proportions of current CS that had made 'quit attempts' was low. EC and HTP use were used as aid to quit CS among $<10 \%$ of current CS during their 'quit attempt'. Comparable rates of EC and HTP as an 'aid to quit smoking' were reported from other countries. ${ }^{25 ; 30}$ Recommended methods to quit smoking such as counselling, nicotine replacement therapy, quit line and prescription medicines were also utilized by $<10 \%$ and $2 / 3 \mathrm{rd}$ of them had tried to 'quit without assistance'. ${ }^{29} \mathrm{~A}$ similar pattern of cessation methods use by current smokers were reported from European countries. ${ }^{30}$ Attempts to quit smoking without any assistance calls for prioritizing provision recommended cessation methods services to reduce the current pool of CS also as tobacco control measure. General lack of intention to quit among current CS can be explained by the health belief model. ${ }^{31}$ The reasons for 'no intention to quit' such as 'lack of confidence to quit' (selfefficacy), 'do not believe that CS is injurious to health' (perceived severity) and poorer knowledge on harms among current CS underscores that need for health promotion interventions to improve health behaviors. Romanian tobacco regulations are well within a broad framework of WHO-FCTC, however, quitting services and their uptake appear suboptimal. ${ }^{32}$

Our results showed that EC and HTP were used to overcome smoke-free policies that are strictly implemented in Romania. A high proportion of 'dual users' and reasons cited for use of EC and HTP suggest that EC or HTP are used by current CS to fulfil 'nicotine cravings' at smoke-free situations. CS and EC are prohibited in the public transport. ${ }^{32}$ However, use of EC at work and public places is still allowed and currently regulations on HTP do not exist. ${ }^{32}$ Varying levels of exposure to secondhand aerosols of EC in European countries were reported in indoor areas explains the EC and HTP use in places where CS is prohibited. ${ }^{33} \mathrm{EC}$ and HTP are also used for reasons other than quitting CS. ${ }^{27}$ In Romania, only half considered EC and HTP as harmful. More than $50 \%$ of smokers perceived e-cigarettes to be equally same or more harmful than conventional cigarettes. ${ }^{34}$ Regardless of smokers' perception on harmfulness, extended use of any type of tobacco product should be discouraged. Replacement by safer alternatives and reduction in smoking intensity does not discount the risk of early death. ${ }^{7}$

After adjusting for socio-demographic factors, 'quit attempt' and smoking $>20$ sticks per day had higher odds of being ever user of EC. This suggests of possible prior unsuccessful attempts to quit smoking with aid of EC perhaps from user perception that ECs are less harmful. 'Smoke-free' rules at home, knowledge about health complications and exposure to information about dangers of smoking, had lower odds of CS, implying that greater awareness and strict rules about CS at home had lower odds of CS. Smoke-free home rules has been shown to reduce smoking intensity in 20 GATS countries. ${ }^{35}$ In GATS 
2018 , Romanian adults were aware of about eight of the 10 health effects of smoking, and nearly twothirds were exposed at least to one source of information about dangers of smoking. ${ }^{29}$ GATS-based report has shown that anti-smoking messages seen on the media increased the knowledge about harms of smoking. ${ }^{36}$ However, exposure to promotional materials about cigarettes increased the odds of CS. Despite the general ban on advertisement with an exception for point-of-sale of tobacco products, ${ }^{32}$ a third of the adults reported to have seen promotional material in stores selling cigarettes (not limited to tobacco stores exclusively) and on the internet. ${ }^{29}$

\section{Policy Implications}

Romania GATS 2018 results provide a policy platform for improving upon the provision of existing tobacco cessation methods and emphasizing dissemination of anti-smoking messages for all types of tobacco products to promote and increase the demand for cessation behaviors among current users of cigarettes as well as EC and HTP. In Romania, EC and HTP were primarily used for reasons other than as aids to smoking cessation, like other European countries. ${ }^{27 ; 37}$ Current tobacco regulations must be made more comprehensive to include stricter regulations on EC and to introduce regulation on HTP. ${ }^{38}$ Furthermore, EC and HTP must be included in smoke-free policies as per European Tobacco Products Directive (TPD) ${ }^{38}$ Stringent implementation of regulation regarding exposure to pro-tobacco sales at point of sales and via internet is required. ${ }^{39}$

\section{Strengths And Limitations}

High response rate (88\%) and a nationally representative larger sample provides more accurate estimates for Romania than other regional surveys. ${ }^{14 ; 22 ; 40}$ However, self-reported tobacco use behaviors are known to have social desirability bias leading to underestimation. ${ }^{41}$ As GATS survey is a cross-sectional design, changes in tobacco use behaviors could not be reported, such as long-term abstinence, quit rates and switching between tobacco products. The association of 'ever use' of EC and HTP lacked statistical power due to smaller sample sizes. Deeper insights into reasons for lack of intention to quit CS and current use of EC and HTP could not be provided due to limited options in GATS questionnaire. Qualitative exploration is required to understand user perceptions about tobacco products. ${ }^{42}$

\section{Conclusion}

Romania GATS 2018 showed that cigarette smoking cessation behaviors were poor and CS prevalence was consistently high as in previous years. Entry of EC and HTP into the market has led to the emergence of 'dual use' and 'polytobacco use' among current CS. EC and HTP were not mainly used to quit smoking but to circumvent smoke-free policies. Comprehensive tobacco control policies inclusive of EC and HTP are required. Measures to increase the demand for and provision of supportive smoking cessation services should be implemented to achieve a 'tobacco free generation.' 
Contributors SH- conceptualization, preparation of tables and figures, co-drafted the manuscript. CTSconceptualization, data analyses, co-drafted the manuscript

\section{Declarations}

Contributors $\mathrm{SH}$ - conceptualization, preparation of tables and figures, co-drafted the manuscript. CTSconceptualization, data analyses, co-drafted the manuscript

Funding No funding for preparing this report

Competing interests none declared

Ethics approval Ethical boards of National Institute of Public Health, Romani and Centre for Disease Control, Atlanta, USA.

\section{References}

1. Proctor, R. N. The history of the discovery of the cigaretteGÇôlung cancer link: evidentiary traditions, corporate denial, global toll. Tobacco control 2012; 21(2):87-91

2. Murray, C. J. et al. Global burden of 87 risk factors in 204 countries and territories, 1990GÇô2019: a systematic analysis for the Global Burden of Disease Study 2019. The Lancet, 396 (10258), 12231249 (2020).

3. Reitsma, M. B. et al. Spatial, temporal, and demographic patterns in prevalence of smoking tobacco use and attributable disease burden in 204 countries and territories, 1990GÇô2019: a systematic analysis from the Global Burden of Disease Study 2019. The Lancet 2021

4. Thomson, G., Edwards, R., Wilson, N. \& Blakely, T. What are the elements of the tobacco endgame? Tobacco control, 21 (2), 293-295 (2012).

5. Fried, N. D. \& Gardner, J. D. Heat-not-burn tobacco products: an emerging threat to cardiovascular health. American Journal of Physiology-Heart and Circulatory Physiology, 319 (6), H1234-H1239 (2020).

6. Simonavicius, E., McNeill, A., Shahab, L. \& Brose, L. S. Heat-not-burn tobacco products: a systematic literature review. Tobacco control, 28 (5), 582-594 (2019).

7. Stratton, K., Kwan, L. Y. \& Eaton, D. L. Public health consequences of e-cigarettes: consensus study report. Public health consequences of e-cigarettes: consensus study report 2018

8. Zakiyah, N. et al. Effectiveness and Safety Profile of Alternative Tobacco and Nicotine Products for Smoking Reduction and Cessation: A Systematic Review. Journal of Multidisciplinary Healthcare 2021; 14:1955

9. Rutten, L. J. F. et al. Use of e-cigarettes among current smokers: associations among reasons for use, quit intentions, and current tobacco use. Nicotine Tob. Res, 17 (10), 1228-1234 (2015). 
10. Bentivegna, K., Atuegwu, N. C., Oncken, C., DiFranza, J. R. \& Mortensen, E. M. Electronic cigarettes associated with incident and polysubstance use among youth. Journal of Adolescent Health, 68 (1), 123-129 (2021).

11. Petersen, A., Myers, M. G., Tully, L., Brikmanis, K. \& Doran, N. Polytobacco use among young adult smokers: prospective association with cigarette consumption. Tobacco control, 29 (1), 43-48 (2020).

12. Chan, G. C. et al. Gateway or common liability? A systematic review and metaGÇÉanalysis of studies of adolescent eGÇÉcigarette use and future smoking initiation., 116 (4), 743-756 (2021).

13. Martinelli, T. et al. Exploring the gateway hypothesis of e-cigarettes and tobacco: a prospective replication study among adolescents in the Netherlands and Flanders. Tobacco control 2021

14. Gallus, S. et al. Use and awareness of heated tobacco products in Europe. Journal of Epidemiology2021;JE20200248

15. Nyman, A. L. et al. Awareness and use of heated tobacco products among US adults, $2016 \mathrm{GÇô2017.}$ Tobacco control, 27 (Suppl 1), s55-s61 (2018).

16. Odani, S. \& Tabuchi, T. Prevalence of heated tobacco product use in Japan: the 2020 JASTIS study. Tobacco control2021

17. Tattan-Birch, H., Brown, J., Shahab, L. \& Jackson, S. E. Trends in use of e-cigarette device types and heated tobacco products from 2016 to 2020 in England. Sci. Rep, 11 (1), 1-11 (2021).

18. Bozier, J. et al. The evolving landscape of e-cigarettes: a systematic review of recent evidence., 157 (5), 1362-1390 (2020).

19. Pisinger, C., Katsaounou, P. \& Belo Ravara, S. E-cigarettes, heated tobacco and other novel nicotinecontaining products: a help to smokers or a public health threat? Supporting Tobacco Cessation (ERS Monograph) Sheffield, European Respiratory Society2021;33-55

20. World Health Organization. WHO framework convention on tobacco control (WHO Regional Office for South-East Asia, 2004).

21. http://ensp.network/conclusions-of-a-quantitative-survey-of-the-public-opinion-on-tobacco-controlpolicies/. 2021

22. Gallus, S. et al. Who smokes in Europe? Data from 12 European countries in the TackSHS survey (2017GÇô2018).Journal of Epidemiology2020;JE20190344

23. Filippidis, F. T., Laverty, A. A., Gerovasili, V. \& Vardavas, C. I. Two-year trends and predictors of ecigarette use in 27 European Union member states. Tobacco control, 26 (1), 98-104 (2017).

24. Maria Lotrean, L. et al. Awareness and use of heated tobacco products among adult smokers in six European countries: findings from the EUREST-PLUS ITC Europe Surveys. European Journal of Public Health, 30 (Supplement_3), iii78-iii83 (2020).

25. Gravely, S. et al. Self-reported quit aids and assistance used by smokers at their most recent quit attempt: Findings from the 2020 International Tobacco Control Four Country Smoking and Vaping Survey. Nicotine \& Tobacco Research 2021 
26. Ryu, D. H., Park, S. W. \& Hwang, J. H. Association between Intention to Quit Cigarette Smoking and Use of Heated Tobacco Products: Application of Smoking Intensity Perspective on Heated Tobacco Product Users. International Journal of Environmental Research and Public Health, 17 (22), 8471 (2020).

27. Xu, S. S. et al. Reasons for regularly using heated tobacco products among adult current and former smokers in Japan: finding from 2018 ITC Japan Survey. International Journal of Environmental Research and Public Health, 17 (21), 8030 (2020).

28. Palipudi, K. M. et al. Methodology of the global adult tobacco surveyGÇö2008GÇô2010. Global health promotion, 23 (2_suppl), 3-23 (2016).

29. Global Adult Tobacco Survey 2018 Romania. 2021

30. Papadakis, S. et al. Quitting behaviours and cessation methods used in eight European Countries in 2018: findings from the EUREST-PLUS ITC Europe Surveys. European Journal of Public Health, 30 (Supplement_3), iii26-iii33 (2020).

31. Kirscht, J. P. The health belief model and predictions of health actions. Health behavior2741(Springer, 1988).

32. https://. 2021

33. Amalia, B. et al. Exposure to secondhand aerosol of electronic cigarettes in indoor settings in 12 European countries: data from the TackSHS survey. Tobacco control, 30 (1), 49-56 (2021).

34. Gravely, S. et al. European adult smokersGÇÖ perceptions of the harmfulness of e-cigarettes relative to combustible cigarettes: cohort findings from the 2016 and 2018 EUREST-PLUS ITC Europe Surveys. European Journal of Public Health, 30 (Supplement_3), iii38-iii45 (2020).

35. Owusu, D., Quinn, M., Wang, K., Williams, F. \& Mamudu, H. M. Smokefree home rules and cigarette smoking intensity among smokers in different stages of smoking cessation from 20 low-and-middle income countries. Preventive medicine, 132, 106000 (2020).

36. Chiosi, J. J. et al. Warning about the harms of tobacco use in 22 countries: findings from a crosssectional household survey. Tobacco control, 25 (4), 393-401 (2016).

37. McDermott, M. S. et al. Social norms for e-cigarettes and smoking: associations with initiation of ecigarette use, intentions to quit smoking and quit attempts: findings from the EUREST-PLUS ITC Europe Surveys. European Journal of Public Health, 30 (Supplement_3), iii46-iii54 (2020).

38. Chung-Hall, J. et al. Support for e-cigarette policies among smokers in seven European countries: longitudinal findings from the 2016GÇô18 EUREST-PLUS ITC Europe Surveys. European Journal of Public Health, 30 (Supplement_3), iii68-iii77 (2020).

39. Kahnert, S. et al. Impact of the Tobacco Products Directive on self-reported exposure to e-cigarette advertising, promotion and sponsorship in smokersGÇöfindings from the EUREST-PLUS ITC Europe Surveys. European Journal of Public Health, 30 (Supplement_3), iii55-iii61 (2020).

40. Thompson, M. E. et al. Methods of the International tobacco control (ITC) EUREST-PLUS ITC Europe surveys. European Journal of Public Health, $\mathbf{3 0}$ (Supplement_3), iii4-iii9 (2020). 
41. Tennekoon, V. \& Rosenman, R. Bias in measuring smoking behavior. School of Economic Sciences Working Paper 2013; 10

42. Robertson, L. et al. Dual use of electronic nicotine delivery systems (ENDS) and smoked tobacco: a qualitative analysis. Tobacco control, 28 (1), 13-19 (2019).

\section{Figures}

\section{Figure 1}

Intentions, attempts to quit and reasons for 'no intention to quit among current CS'.

\section{Figure 2}

Awareness, current use and reasons for current of EC and HTP

\section{Supplementary Files}

This is a list of supplementary files associated with this preprint. Click to download.

- AppendicesAandB.docx 